\title{
KALAFUNGIN. II. CHEMICAL TRANSFORMATIONS AND THE ABSOLUTE CONFIGURATION
}

\author{
H. Hoeksema and W. C. Krueger \\ The Upjohn Company, Kalamazoo, Michigan 49001, U.S. A. \\ (Received for publication May 4, 1976)
}

\begin{abstract}
The properties of number of kalafungin derivatives and analogues are consistent with the proposed structure. The absolute stereochemistry of the three active centers was determined to be RRR by optical rotatory dispersion comparisons.
\end{abstract}

The isolation of the antifungal antibiotic kalafungin has been reported. ${ }^{1)}$ Subsequently, DuCHAmp2) has described the molecular structure and the relative configuration of its three stereochemical centers. In this paper we present chemical and physical data which support this structure and additionally have enabled us to assign the absolute configuration as that represented by 1a, Fig. 1. The latter was adduced from optical rotatory dispersion comparisons with the known substances eleutherin ${ }^{3)}$ and isoeleutherin. ${ }^{4)}$

Fig. 1. Structure of kalafungin.

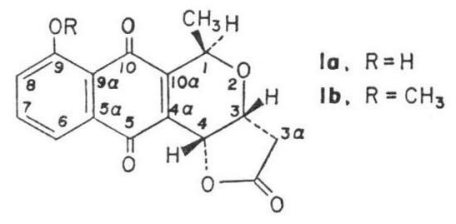

\section{Chemical and Spectroscopic Considerations}

The molecular formula of kalafungin, $\mathrm{C}_{10} \mathrm{H}_{12} \mathrm{O}_{8}$, requires 11 sites of unsaturation. The orange color which disappears reversibly upon catalytic or chemical reduction, characteristic ultraviolet absorptions at 212, 256, $268(\mathrm{sh})$ and $425 \mathrm{~nm}$, and infrared bands at 1666, 1653, 1648 and $1625 \mathrm{~cm}^{-1}$ are consistent with the naphthoquinone structure. The phenolic $\mathrm{OH}$ is represented by an acidic function, pKá $=10$. The absence of characteristic hydroxyl absorptions in the infrared spectrum suggests extensive H-bonding.

Methylation of the hydroxyl function with diazomethane failed, presumably due to this hydrogen bonding. With methyl iodide and silver oxide, however, 9-O-methylkalafungin, 1b, was formed and the resulting hypsochromic ultraviolet shifts for $\mathbf{1 b}$ support existence of an aromatic hydroxyl function. Absence of absorptions at $495 \sim 500 \mathrm{~nm}$ for $\mathbf{1 b}$ favors the 1,4naphthoquinone, not a 1,2 isomer. ${ }^{5,8)}$ Ultraviolet and PMR data supported a peri hydroxyl as shown by comparisons with corresponding data from juglone.

In base, kalafungin was rapidly transformed to kalafunginic acid, 2a, (Fig. 2) which lacks characteristic lactone absorption at $1760 \mathrm{~cm}^{-1}$. Upon acidification under conditions in which the product remains in solution the lactone re-forms. Treatment of kalafungin with ethanolic hydrogen chloride afforded the ester, $\mathbf{2} \mathbf{b}$, as well as additional products including an ester in which the newly formed hydroxyl is replaced by chlorine, 3, and an elimination product, 4, which was particulary favored by heating. These latter transformations are reflected in the NMR signals for the system involving carbons $\mathbf{3}, \mathbf{3} \boldsymbol{a}$, and $\mathbf{4}$ (Table 1). In compounds $\mathbf{2 a}, \mathbf{2 b}$, 
Fig. 2. Kalafungin transformation products and related compounds.

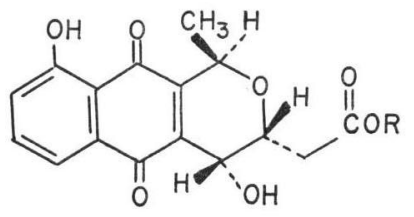

2a $\quad \mathrm{R}=\mathrm{H}$

2b $\quad R=\mathrm{C}_{2} \mathrm{H}_{5}$<smiles>CCOC(=O)CC1=CC2=C(C(=O)c3c(O)cccc3C2=O)C(C)O1</smiles>

4<smiles>[R7]C1([R])CC2=C(C(=O)c3c(OC)cccc3C2=O)C([2H])(C)O1</smiles><smiles>CCOC(=O)C[C@H]1O[C@H](C)C2=C(C(=O)c3cccc(O)c3C2=O)C1Cl</smiles>

3<smiles>C[C@H]1O[C@H]2CC(=O)O[C@@]23COC32C3=C(C(=O)c4c(O)cccc43)C12</smiles>

5

60 Eleutherin $\mathrm{R}_{1}=\mathrm{CH}_{3}, \mathrm{R}_{2}=\mathrm{H}$

6 b Isoeleutherin $\mathrm{R}_{1}=\mathrm{H}, \mathrm{R}_{2}=\mathrm{CH}_{3}$

and 3, which now have equivalent hydrogens at $3 a$, one doublet representing both hydrogens, in distinction from the situation for $\mathbf{1 a}, \mathbf{b}$ in which the individual hydrogens can be distinguished. With the loss of the $\mathrm{C}-3$ hydrogen in the unsaturated ester 4 , these $3 \alpha$-hydrogens appear as a singlet.

As mentioned earlier, treatment of 1a with diazomethane fails to methylate the hydroxyl group. However, kalafungin dissolved in tetrahydrofuran did react with ethereal diazomethane affording 5. Disappearance of infrared absorptions at 1625 and $1666 \mathrm{~cm}^{-1}$ and hypsochromic ultraviolet shifts indicated disruption of the quinonoid system. Appearance of two new signals in the PMR spectrum at $\delta 1.9$ and $\delta 2.2 \mathrm{ppm}$ coupled to each other, $\mathrm{J}=5.5 \mathrm{~Hz}$, then suggests addition of the methylene across a carbonyl to form an oxirane group. It seems likely that the non-hydrogen-bonded carbonyl as shown in $\mathbf{5}$ would be the most amenable candidate for such a transformation, and this is supported by PMR information. A downfield shift of the C-4 doublet from $\delta 5.2$ to $\delta 5.5$ is explainable by enhancement of the conjugated carbonyl system to which it is allylic. On the other hand an upfield shift from $\delta 5.1$ to $\delta 4.8 \mathrm{ppm}$ of the signals ascribed to the $\mathrm{C}-1$ hydrogens would ostensibly be due to increased shielding consequential to loss of conjugation between the allylic position and the former carbonyl.

\section{Absolute Configuration of Kalafungin}

The configuration of kalafungin at positions 1,3, and 4 would be RRR or SSS according to the crystallographic studies. ${ }^{2)}$ A comparison of the kalafungin optical rotatory dispersion curves with those of two model compounds of known configurations and conformations has 
Table 1. NMR Data for kalafungin compounds*

\begin{tabular}{|c|c|c|c|c|c|c|c|}
\hline Compound number & & 1h & ? & & & & \\
\hline Molecular position & (Kalafungin) & 10 & $2 a$ & $2 \mathrm{~b}$ & 3 & 4 & 5 \\
\hline $1 \mathrm{a}, 3 \mathrm{H}$ & $\delta 1.52, \mathrm{~d}, \mathrm{~J}_{1} 7$ & $\delta 1.48, \mathrm{~d}, \mathrm{~J}_{1} 7$ & $\delta 1.52, \mathrm{~d}, \mathrm{~J}_{1} 7$ & $\delta 1.53, \mathrm{~d}, \mathrm{~J}_{1} 7$ & $\delta 1.6, \mathrm{~d}, \mathrm{~J}_{1} 7$ & $\delta 1.46, \mathrm{~d}, \mathrm{~J}_{1} 6.5$ & $\delta 1.53, \mathrm{~d}, \mathrm{~J}_{1} 6.5$ \\
\hline $1,1 \mathrm{H}$ & $\delta 5.05, \mathrm{q}, \mathrm{J}_{1 a} 7$ & $\delta 4.92, \mathrm{q}, \mathbf{J}_{1 a} 7$ & $\delta 4.87, \mathrm{q}, \mathrm{J}_{1 a} 7$ & $\delta 5.00, \mathbf{q}, \mathbf{J}_{1 a} 7$ & $5.15, \mathbf{q}, \mathbf{J}_{1 a} 7$ & $\delta 5.48, \mathrm{q}, \mathrm{J}_{1 a} 6.5$ & $\delta 4.75, \mathbf{q}, \mathbf{J}_{1 a} 6.5$ \\
\hline $3,1 \mathrm{H}$ & $\begin{array}{r}\delta 4.69, \mathrm{dt}, \mathrm{J}_{3 \alpha} 4.5 \\
\mathrm{~J}_{4} 3.0\end{array}$ & $\begin{array}{r}\delta 4.68, \mathrm{dt}, \mathrm{J}_{3 \alpha} 5.0 \\
\mathrm{~J}_{4} 3.0\end{array}$ & $\begin{array}{r}\delta 4.28, \mathrm{dt}, \mathrm{J}_{3 \alpha} 5.0 \\
\mathrm{~J}_{4} 2.0\end{array}$ & $\begin{array}{r}\delta 4.32, \mathrm{dt}, \mathbf{J}_{3 \alpha} 6.5 \\
\mathbf{J}_{4} 2.0\end{array}$ & $\begin{array}{r}\delta 4.58, \mathrm{dt}, \mathbf{J}_{3 \alpha} 6.0 \\
\mathrm{~J}_{4} 2.0\end{array}$ & - & $\begin{array}{r}\delta 4.52, \mathrm{dt}, \mathbf{J}_{3 \alpha} 5.0 \\
\mathrm{~J}_{4} 4.5\end{array}$ \\
\hline $3 \alpha_{1} 1 \mathrm{H}$ & $\delta 2.57, \mathrm{~d}, \mathbf{J}_{3 \alpha_{2}} 18$ & $\delta 2.46, \mathrm{~d}, \mathbf{J}_{3 \alpha_{2}} 18$ & $\delta 2.75, \mathrm{~d}, \mathrm{~J}_{3} 5.0$ & $\delta 2.80, \mathrm{~d}, \mathbf{J}_{3} 6.5$ & $\delta 2.84, \mathrm{~d}, \mathrm{~J}_{3} 6.0$ & $\delta 3.28, \mathrm{~s}$ & $\delta 2.48, \mathrm{~d}, \mathbf{J}_{3 \alpha_{2}} 18$ \\
\hline $3 \alpha_{2} 1 \mathrm{H}$ & $\begin{array}{r}\delta 3.02, \mathrm{dd}, \mathrm{J}_{3 \alpha_{1}} 18 \\
\mathrm{~J}_{3} 4.5\end{array}$ & $\begin{array}{r}3.50, \mathrm{dd}, \mathbf{J}_{3 \alpha_{1}} 18 \\
\mathbf{J}_{3} 5.0\end{array}$ & $\delta 2.75, \mathrm{~d}, \mathrm{~J}_{3} 5.0$ & $\delta 2.80, \mathrm{~d}, \mathbf{J}_{3} 6.5$ & $\delta 2.84, \mathrm{~d}, \mathrm{~J}_{3} 6.0$ & $\delta 3.28, \mathrm{~s}$ & $\begin{array}{r}\delta 2.93, \mathrm{dd}, \mathbf{J}_{3 \alpha_{1}} 18 \\
\mathbf{J}_{3} 5.0\end{array}$ \\
\hline $4,1 \mathrm{H}$ & $\delta 5.20, \mathrm{~d}, \mathrm{~J}_{3} 3.0$ & $5.28, \mathrm{~d}, \mathrm{~J}_{3} 3.0$ & $\delta 4.90, \mathrm{~d}, \mathrm{~J}_{3} 2.0$ & $\delta 4.65, \mathrm{~d}, \mathbf{J}_{3} 2.0$ & $\delta 5.15, \mathrm{~d}, \mathrm{~J}_{3} 2.0$ & $\delta 6.00, \mathrm{~s}$ & $\delta 5.52, \mathrm{~d}, \mathbf{J}_{3} 4.5$ \\
\hline $6,7,8,3 \mathrm{H}$ & $\delta 7.00 \sim 7.78, \mathrm{~m}$ & $7.42 \sim 8.00, \mathrm{~m}$ & $\delta 7.25 \sim 8.00, \mathrm{~m}$ & $\delta 7.06 \sim 7.67, \mathrm{~m}$ & $\delta 7.00 \sim 7.74, \mathrm{~m}$ & $\delta 7.05 \sim 7.67, \mathrm{~m}$ & $\delta 7.08 \sim 7.70, \mathrm{~m}$ \\
\hline $\mathrm{OH}, 4-\mathrm{OH}$ & - & - & $\delta 2.75$ & $\delta 2.80$ & & & \\
\hline 9-OH & $\delta 11.80$ & - & $\delta 11.84$ & $\delta 11.84$ & $\delta 12.00$ & $\delta 12.02$ & $\delta 11.79$ \\
\hline Other & & $\begin{array}{l}\text { 9-O-methyl } 3 \mathrm{H} \\
\delta 3.93, \mathrm{~s}\end{array}$ & $\begin{array}{l}\text { Carboxyl OH 1H } \\
\delta 5.00\end{array}$ & $\begin{array}{c}\text { Ester ethyl } \\
\delta 1.30 \text {, t, J } 7.5 \\
\delta 4.21, \mathrm{q}, \mathrm{J} 7.5\end{array}$ & $\begin{array}{c}\text { Ester ethyl } \\
\delta 1.31 \text {, t, J } 7.5 \\
\delta 4.24, \mathrm{t}, \mathrm{J} 7.5\end{array}$ & $\begin{array}{c}\text { Ester ethyl } \\
\delta 1.30, \mathrm{t}, \mathrm{J} 7.5 \\
\delta 4.22, \mathrm{t}, \mathrm{J} 7.5\end{array}$ & $\begin{array}{c}\text { Oxirane, } 5 \alpha \\
\delta 1.87, \text { d, } \mathbf{J}_{5 \alpha_{2}} 5.2 \\
\delta 2.24, \mathrm{~d}, \mathbf{J}_{5 \alpha_{1}} 5.2\end{array}$ \\
\hline
\end{tabular}


now permitted us to establish the absolute configuration. Kalafungin contains two inherently symmetric chromophores which are asymmetrically perturbed, the 1,4-napthoquinone system and the lactone carbonyl. The 1,4-naphthoquinone system is present in the two model compounds, eleutherin, $\mathbf{6 a}$, and isoeleutherin, $\mathbf{6 b}$. $\mathbf{S C H M I D}^{3,8)}$ determined the absolute configuration

Fig. 3. Conformation of kalafungin and model compounds.
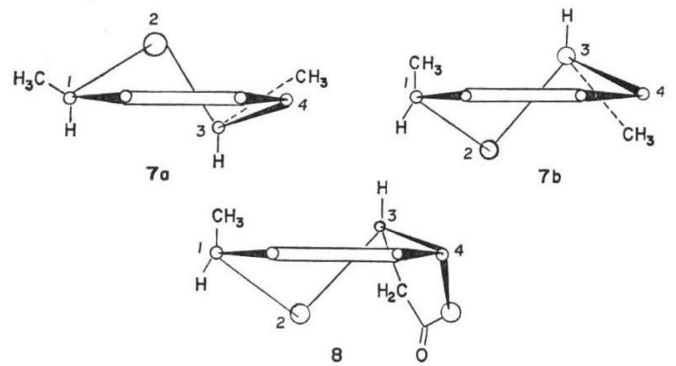

Fig. 4. Molar extinction coefficient vs. wavelength.

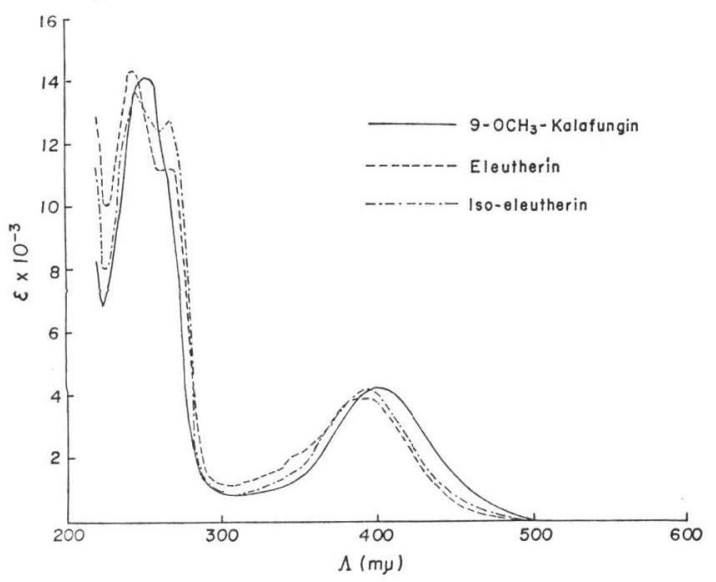

Fig. 5. Molecular rotation vs. wavelength.

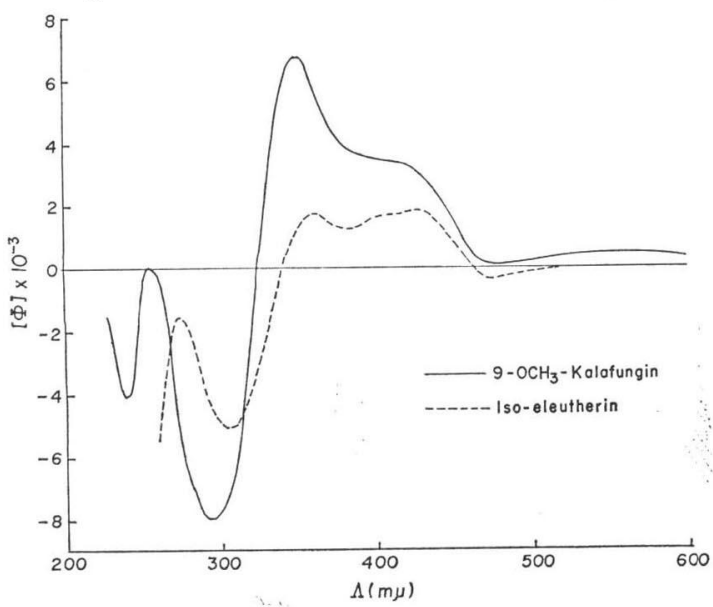

of these compounds. PMR studies by CAMERoN et $a l^{9)}$ indicated that the heterocyclic ring of eleutherin is inverted in respect to isoeleutherin, depicted by the partial formulas $7 \mathbf{a}$ and $\mathbf{7 b}$ (Fig. 3) as viewed through the fused napthoquinone double bond. The steric strain otherwise resulting from two axial groups is thus relieved.

Studies with space-filling models show that while eleutherin is somewhat unstable in the half-chair conformation due to steric strain between the 1-methyl and neighboring carbonyl groups, isoeleutherin is strain-free in this conformation. If we assume for the argument, the RRR configuration for kalafungin, we find that this molecule is locked in a similar halfchair conformation by the lactone-imposed rigidity, as in partial formula 8. Aside from the lactone group in 9-O-methyl kalafungin (1b), the perturbing groups of it and of isoeleutherin would be the same. The two ORD curves, then, should be similar for the similar configurations (RRR), and would be mirror images if kalafungin is SSS. The comparisons of the ultraviolet curves (Fig. 4) and the ORD curves (Fig. 5) for 9-O-methyl kalafungin and isoeleutherin show significant similarities. Since the lactone group absorbs at much lower wave-length, it should not interfere with this comparison, and therefore the absolute configuration for kalafungin is $R R R$ as shown in 1a. The greater rotatory strength of kalafungin, which has more perturbing groups in the same region and is a more rigid molecule, is expected.

Structural similarities place kalafungin in the same family with frenolicin ${ }^{10)}$ and the recently described nanaomycins $\mathrm{A}$ and $\mathrm{B} .{ }^{11}$ 


\section{Biological Activity}

All of the kalafungin analogs except $\mathbf{5}$ displayed characteristic kalafungin antifungal activity, but none of them was active as the parent antibiotic.

\section{Experimental*}

9-O-Methyl Kalafungin (1b).

Kalafungin $(3 \mathrm{~g}, 10 \mathrm{mmol})$ and a large excess of methyl iodide $(150 \mathrm{ml})$ were dissolved in $150 \mathrm{ml}$ of dry acetone. This solution was refluxed and $1.5 \mathrm{~g}(6.5 \mathrm{mmol})$ of silver oxide was carefully added. Second and third $1.5 \mathrm{~g}$ portions of silver oxide were added one and two hours later respectively. The reaction course was followed by tlc, and with the disappearance of starting material, refluxing was discontinued. The mixture was filtered, the filtrate was made slightly acidic with $0.1 \mathrm{~N} \mathrm{HCl}$, and the solvent was evaporated on a rotary evaporator. The residue was crystallized from acetone yielding yellow crystals, mp $205 \sim 215^{\circ} \mathrm{C} \mathrm{dec}$. $(2.16 \mathrm{~g}, 6.9$ $\mathrm{mmol})$.
Anal. Calcd. for $\mathrm{C}_{17} \mathrm{H}_{14} \mathrm{O}_{6}$ :
C, 64.97; H, 4.49; Mol. Wt. 314 .
Found:
C, $65.05 ; \mathrm{H}, 4.84$; Mol. Wt. $\mathrm{M}^{+} 314$.

Kalafunginic Acid (2a).

A $1 \mathrm{~g}(3.33 \mathrm{mmol})$ quantity of kalafungin was dissolved with stirring in $10 \mathrm{ml}$ of $1 \mathrm{~N} \mathrm{NaOH}$. Upon complete dissolution, $11 \mathrm{ml}$ of $1 \mathrm{~N} \mathrm{HCl}$ was added and a precipitate formed. A chloroform extract of this precipitate was washed with water, dried $\left(\mathrm{Na}_{2} \mathrm{SO}_{4}\right)$, and evaporated to dryness. The residue was crystallized from ethyl acetate, $\mathrm{mp} 182^{\circ} \mathrm{C} \mathrm{dec} .(530 \mathrm{mg}, 1.7 \mathrm{mmol})$.

Anal. Calcd. for $\mathrm{C}_{18} \mathrm{H}_{14} \mathrm{O}_{7}$ : C, $60.38 ; \mathrm{H}, 4.43$.

Found: $\quad$ C, $60.35 ; \mathrm{H}, 4.78$.

Reconversion of Kalafunginic Acid to Kalafungin.

Kalafunginic acid $(1 \mathrm{~g}, 3.1 \mathrm{mmol})$ was dissolved in $150 \mathrm{ml}$ of $2 \mathrm{~N}$ ethanolic $\mathrm{HCl}$. After 20 minutes this solution was evaporated to dryness on the rotary evaporator. The residue was chromatographed in ethyl acetate-cyclohexane $(3: 5, \mathrm{v} / \mathrm{v})$ on $150 \mathrm{~g}$ of silica gel. The progress of this column was monitored by tlc and two fraction pools were accumulated and evaporated to residues which were then crystallized from chloroform, and Skellysolve B. These were identified by $\mathrm{nmr}$ comparisons. Fraction A $(130 \mathrm{mg}, 0.38 \mathrm{mmol})$ was identical with ethyl kalafunginate, while Fraction B $(370 \mathrm{mg}, 1.2 \mathrm{mmol})$ was identical with kalafungin.

Ethyl Kalafunginate (2b) and Ethyl-4-chloro-4-deoxykalafunginate (3).

A solution of kalafungin $(5.0 \mathrm{~g}, 16.7 \mathrm{mmol})$ in $500 \mathrm{ml}$ of $2 \mathrm{~N}$ ethanolic hydrogen chloride was stored at room temperature for 1.5 hours, then rapidly evaporated on a rotary evaporator in vacuo. The residue as analyzed by tlc contained at least three substances, one of which appeared to be unreacted kalafungin. These compounds were separated by chromatography in ethylacetate-cyclohexane $(3: 5, \mathrm{v} / \mathrm{v})$ over silica and isolated by evaporation of the appropriate fraction pools as analyzed by tlc. All three residues were crystallized from chloroform : Skellysolve B mixtures.

Ethyl kalafunginate: $3.0 \mathrm{~g}, 8.7 \mathrm{~mol}, \mathrm{mp} 127^{\circ}[\alpha]_{\mathrm{D}} 130^{\circ}$ (c 1, chloroform).

Anal. Calcd. for $\mathrm{C}_{18} \mathrm{H}_{18} \mathrm{O}_{7}:$ C, 62.42; H, 5.24 .

Found: $\quad$ C, $62.25 ; \mathrm{H}, 5.14$.

Ethyl 4-chloro-4-deoxykalafunginate: $365 \mathrm{mg}, 1 \mathrm{mmol}, \mathrm{mp} 130 \sim 133^{\circ} \mathrm{C}$. Mass spectrometry indicates one atom of chlorine and a molecular weight 364. Nmr located 17 hydrogen atoms, $\mathrm{C}_{18} \mathrm{H}_{17} \mathrm{O}_{8} \mathrm{Cl}$.

* Melting points are not corrected. NMR spectra were recorded on a Varian A-60 spectrophotometer. Thin-layer chromatography (tlc) was performed on silica gel, GF precoated (Analtech), and detection of spots carried out by UV-irradiation. 
Unreacted kalafungin: $350 \mathrm{mg}, 1.2 \mathrm{mmol}, \mathrm{mp} 126 \sim 127^{\circ} \mathrm{C}$. Identified from nmr comparison with an authentic sample.

Ethyl Kalafungenate (4).

A solution of kalafungin $(1 \mathrm{~g}, 3.33 \mathrm{mmol})$ in $150 \mathrm{ml}$ of $2 \mathrm{~N}$ ethanolic $\mathrm{HCl}$ was refluxed for two hours. The reaction was monitored by tlc, showing formation of two intermediates, one more and one less polar than kalafungin, and a final product much less polar than all of them. The solution was evaporated to dryness on a rotary evaporator yielding $1 \mathrm{~g}$ of residue. This was chromatographed with ethylacetate-cyclohexane $(1: 4, \mathrm{v} / \mathrm{v})$ over $200 \mathrm{~g}$ of silica gel. The fraction pool containing the least polar component was evaporated and the residue crystallized from Skellysolve B, $\mathrm{mp} 104^{\circ} \mathrm{C}(300 \mathrm{mg}, 0.92 \mathrm{mmol})$.

Anal. Calcd. for $\mathrm{C}_{15} \mathrm{H}_{16} \mathrm{O}_{6}$ : C, 65.85; $\mathrm{H}, 4.91$.

Found: $\quad$ C, $65.45 ; \mathrm{H}, 5.05$.

5-Deoxo-5,5-methylenoxy Kalafungin (5).

An ether solution $(15 \mathrm{ml})$ containing diazomethane (excess) prepared from $1.5 \mathrm{~g}(9.5 \mathrm{mmol})$ of $N$-methyl- $N^{\prime}$-nitro- $N$-nitrosoguanidine was added to a solution consisting of $300 \mathrm{mg}(1.0 \mathrm{mmol})$ of kalafungin in $10 \mathrm{ml}$ of dried (alumina) tetrahydrofuran. After six hours the solution was evaporated and the residue was chromatographed with ethyl acetate-cyclohexane $(3: 5, \mathrm{v} / \mathrm{v})$ over silica gel $(30 \mathrm{~g})$. From the appropriate fraction pool as determined by tlc was collected $40 \mathrm{mg}$ of solid which crystallized from ethyl acetate. $\mathrm{mp} 260^{\circ} \mathrm{C},[\alpha]_{\mathrm{D}}-103^{\circ}$ (c 1, $\left.\mathrm{CHCl}_{3}\right)$.

Anal. Calcd. for $\mathrm{C}_{17} \mathrm{H}_{14} \mathrm{O}_{6}$ : C, 64.97; H, 4.19, Mol. Wt. 314.28.

Found: $\quad$ C, $64.70 ; \mathrm{H}, 4.85$, Mol. Wt. $\mathrm{M}^{+} 314$.

\section{References}

1) Bergy, M.E.: Kalafungin, a new broad spectrum antibiotic. Isolation and characterization. J. Antibiotics 21: 454 457, 1968

2) Duchamp, D. J.: The crystal and molecular structure of kalafungin. Amer. Cryst. Assoc. Abstr. Papers, Summer Mtg. 82, 1968

3) Schmid, von H.; A. EbnÖther \& Th. M. Meijer: Über die Konstitution des Eleutherins. Helv. Chim. Acta 33: 1751 1770, 1950

4) SCHMID, von H. \& A. EBNÖTHER: Isolierung und Konstitution des Isoeleutherins. Allo- und Alloisoelutherin. Helv. Chim. Acta 34: 561 569, 1951

5) Macbeth, A.K.; J.R. Price \& F. L. Winzer: The colouring matter of Drosera whittakeri. I. The absorption spectra and colour reactions of hydroxy-naphthoquinones. J. Chem. Soc. 1935: $325 \sim 333,1935$

6) Nagakura, S. \& A. Kuboyama: Dipole moments and absorption spectra of $O$-benzoquinone and its related substances. J. Amer. Chem. Soc. 76: 1003 1005, 1954

7) Both of these compounds were generously supplied by Prof. H. Schmid, University of Zürich.

8) Eisenhuth, W. \& H. Schmid: Synthese der racemischen Eleutherinchinone. Helv. Chim. Acta 41: $2021 \sim 2035,1958$

9) Cameron, D. W.; D. G. I. Kingston, N. Sheppard \& Lord Todd: Colouring matters of the Aphididae. XXII. Nuclear magnetic resonance evidence for the structures and conformations of the naphthoquinone dimethyl ethers derived from the protoaphins and of the erythroaphins. J. Chem. Soc. 1964: 98 104, 1964

10) Ellestad, G. A.; H. A. Whaley \& E. L. Patterson: The structure of frenolicin. J. Amer. Chem. Soc. 88: 4109 4110, 1966

11) Tanaka, H.; Y. Koyama, T. Nagai, H. Marumo \& S. Ōmura: Nanaomycins, new antibiotics produced by a strain of Streptomyces. II. Structure and biosynthesis. J. Antibiotics 28: 868 875,1975 